\title{
A GRÉCIA DE WINCKELMANN
}

\author{
Pedro Süssekind* \\ pedrosuss@gmail.com
}

RESUMO $O$ presente estudo pretende mostrar como se articulam o helenismo e o Classicismo na estética alemã do século XVIII. A obra de Winckelmann será considerada como uma fundamentação do Classicismo helenista alemão da última década desse século, cujo projeto era imitar o ideal de beleza da arte grega.

Palavras-chave Winckelmann; Goethe; Helenismo; Classicismo.

\begin{abstract}
The following work intends to show how Classicism and Hellenism are articulated in the $18^{\text {th }}$ century German aesthetics. Winckelmann's works will be considered as a foundation to German Hellenism and Classicism in the last decade of that century, which was based on the imitation of the ideal of beauty in Greek art.
\end{abstract}

Keywords Winckelmann; Goethe; Classicism; Hellenism.

Apesar de sua grande importância na história da cultura alemã, Johann Joachim Winckelmann (1717-1768) não é um autor muito estudado atualmente, pelo menos não na medida que se esperaria a partir dos comentários feitos por seus contemporâneos ou sucessores. Herder e Goethe escreveram longos

* Professor adjunto do Programa de Pós-Graduação em Arte e Filosofia da UFOP, MG. Artigo recebido em março de 2007 e aprovado em março de 2008.

KRITERION, Belo Horizonte, nº 117, Jun./2008, p. 67-77. 
ensaios em homenagem a ele, Madame de Staël, em seu célebre livro sobre a cultura alemã, chamava a atenção dos leitores franceses para "o homem que fez uma verdadeira revolução na Alemanha na maneira de considerar as artes, e entre elas a literatura". ${ }^{1}$ Contribuem para o declínio do interesse pelas obras de Winckelmann tanto as dificuldades do estilo e da escrita, repleta de referências aos debates travados pelos teóricos da arte da época, quanto a imprecisão, evidenciada à luz de análises posteriores, dos dados históricos fornecidos pelo autor.

Além de ser considerado o fundador da arqueologia moderna, em função de seus estudos das escavações de Pompéia e Herculano, Winckelmann estabeleceu novos parâmetros para a história da arte, influenciando todo o seu desenvolvimento posterior. Segundo os próprios historiadores da arte, ele também teve um papel decisivo no movimento neoclássico, embora esse papel talvez revele uma má interpretação de sua teoria acerca da imitação dos antigos. Como aponta Gerd Bornheim, em seu ensaio "Introdução à leitura de Winckelmann", "os seus autênticos continuadores não são os escultores e os pintores" que seguiram o caminho do academismo e da cópia, "mas os poetas", ${ }^{2}$ sobretudo Goethe em sua fase clássica. De fato, Winckelmann pretendeu indicar um caminho para a produção artística, especialmente no campo da escultura, defendendo o modelo dos gregos antigos, mas as suas idéias não podem ser reduzidas ao princípio que norteou o movimento neoclássico. Elas se inserem em um projeto mais amplo de análise e compreensão da arte grega, um esforço de interpretação que influenciou decisivamente a literatura e a filosofia alemãs nos séculos seguintes.

O texto das Reflexões sobre a imitação das obras gregas na pintura e na escultura, primeira obra de Winckelmann, contém duas noções fundamentais que orientam toda a teoria de seu autor. A primeira delas é basicamente didática, uma vez que a defesa da imitação dos antigos se apresenta como uma recomendação, aos artistas jovens, de que partam do modelo da arte grega, em vez de recorrerem diretamente ao modelo da natureza. Mas, considerada como "o único caminho para nos tornarmos grandes, se possível inimitáveis", a idéia de imitação constitui um dos pilares do Classicismo alemão e se insere na tradição da Querelle dos antigos e dos modernos. A outra noção central na teoria de Winckelmann é a dupla definição do ideal de beleza da arte antiga, caracterizado como nobre simplicidade e calma grandeza. Esse ideal ressaltado pelo autor nas suas descrições das estátuas gregas revelaria a meta

2 BORNHEIM. Páginas de filosofia da arte, p. 106. 
da arte, aquilo que a torna inimitável e, ao mesmo tempo, faz dela um modelo a ser imitado.

Em seu ensaio sobre Winckelmann, escrito em 1805, Goethe chama a atenção para a dificuldade inerente à leitura das Reflexões. Embora considere que o escrito "contém passagens excelentes, de importância fundamental," e "indica corretamente a meta da arte", ele afirma que, "quanto à forma e à matéria, a discussão é tão barroca e estranha que seria impossível dar sentido a ela sem conhecer as personalidades dos eruditos e críticos na Saxônia na época, as opiniões deles, suas inclinações e caprichos...”. Ele se refere aqui a autores como Lippert, Hagedorn, Dietrich e Oeser, todos eles teóricos da arte com quem Winckelmann dialoga em sua primeira obra. $\mathrm{O}$ método didático e anedótico desses autores de meados do século XVIII também teria sido adotado pelo autor das Reflexões. O adjetivo "barroca", atribuído à sua escrita, indica um contra-senso entre o propósito do texto, de criticar justamente o estilo barroco da arte de sua época, e o texto rebuscado, construído em cima de oposições sutis, de considerações às vezes ambíguas. Em função das dificuldades do texto, tanto metodológicas quanto estilísticas, Goethe conclui: “A obra será incompreensível para as próximas gerações, a não ser que amantes da arte próximos ao período a façam acompanhar por descrições detalhadas das condições em que ela surgiu". ${ }^{3}$

No entanto, apesar de suas dificuldades e deficiências, a primeira obra de Winckelmann tinha sido privilegiada por Herder, em lugar da mais completa História da arte da Antigüidade, no texto "Memorial de Johann Winckelmann", de 1777. Para Herder, "de certo modo a primeira obra de um homem será sempre a sua melhor", porque "depois ele pode ganhar muito em maturidade, força, erudição e conhecimento, como Winckelmann indubitavelmente ganhou com o passar dos anos; mas a sua alvorada e primeiro florescimento juvenil foram transmitidos naquela primeira obra". Os defeitos desse escrito "imperfeito" são considerados como qualidades:

Ele abarca mais do que tem, intui mais do que sabe, mas flutua ainda em sonhos ditosos e se entrega. Mais tarde vêm contradições, regras e inimigos que o tornam mais cuidadoso [...], na primeira obra ele trabalha ainda sem limitações, no paraíso que ele cria para si mesmo, as forças de sua alma ainda se encontram sem divisão, e ele pretende, como as crianças que começam a falar, dar tudo de uma vez, dizer tudo de uma vez. ${ }^{4}$

3 GOETHE. Winckelmann. In: Vermischte Schriften, Sechster Band, p. 275. Ver também: GOETHE. Essays on art and literature, v. 3.

4 HERDER. Sämtliche Werke, $451 \mathrm{f}$. 
O texto de Herder procura definir a influência que Winckelmann teve sobre sua própria concepção histórica da arte, vendo no autor das Reflexões um defensor do sentimento contra o racionalismo iluminista. Como teórico do Sturm und Drang, o movimento pré-romântico que ganhava força na Alemanha no final do século XVIII e se opunha sobretudo às regras do Classicismo francês, Herder valorizava o direcionamento de Winckelmann para uma interpretação direta e arrebatada das obras de arte particulares. Assim, a proximidade por meio do sentimento se contrapõe à frieza da razão normativa, e a busca das condições de surgimento da escultura, identificadas na observação da natureza bela dos corpos de atletas, indica um caminho teórico novo, baseado na especificidade da cultura, da geografia e do clima. Uma compreensão desse tipo foi defendida por Herder em seus ensaios sobre arte, especialmente no escrito de 1773 sobre Shakespeare. Mas a perspectiva histórica do autor de Idéias sobre a filosofia da história da humanidade contradizia o caráter de modelo exclusivo da arte grega, por isso Winckelmann também é criticado, no final do ensaio dedicado a ele, em função de sua falta de interesse pela arte do Egito e da Ásia, identificados por Herder como o berço cultural da Grécia antiga.

O crítico literário Peter Szondi cita os comentários de Herder, para justificar sua própria escolha das Reflexões como tema de análise na conferência "Antigos e modernos na estética da época de Goethe”. Segundo a análise de Szondi, o texto das Reflexões situa seu autor na fronteira entre duas épocas da estética: a tradição normativa e classificatória baseada na Poética de Aristóteles, que dominava a teoria da arte iluminista, e a concepção histórica que marcaria a filosofia da arte no século XIX. ${ }^{5}$ A posição de Winckelmann em relação à transição por que passava a estética de sua época se manifestaria já na primeira frase do escrito: "O bom gosto, que se espalha cada vez mais pelo mundo, começou a se formar pela primeira vez sob o céu grego".

Por um lado, a noção de "bom gosto" revela um vínculo com a estética iluminista, na qual o domínio do gosto, como uma espécie de senso clássico de beleza, define um critério normativo atemporal para distinguir as obras de arte boas das ruins. Desde o Renascimento, passando pelo Classicismo francês, tinha havido um refinamento desse critério, a princípio ligado à idéia de autoridade dos autores antigos, determinante no pensamento medieval, depois ao domínio da razão, com a discussão das regras da arte e de suas funções. O bom gosto aparece então como uma capacidade de apreensão do 
belo, anterior à compreensão racional, mas orientada por ela. Por outro lado, a referência que Winckelmann faz ao "céu grego" aponta, ainda de acordo com Szondi, para uma compreensão histórica das condições de surgimento das obras de arte em seu caráter particular, único, ligado ao clima, à natureza do lugar e do povo nele gerado. Essa singularidade da cultura grega é tema da segunda frase do texto das Reflexões:

Todas as invenções de povos estrangeiros vieram para a Grécia, apenas como a primeira semente, e assumiram uma outra natureza e configuração na terra que Minerva, diz-se, reservou aos gregos para morada, de preferência a todas as terras, em função das estações temperadas que encontrou nesse lugar que produziria homens inteligentes.

Para Szondi, desde o início a teoria de Winckelmann é marcada por uma contradição, o que revela seu posicionamento em um momento de transição nas concepções acerca da arte. $\mathrm{O}$ autor das Reflexões inaugura uma compreensão da história da arte baseada na busca das condições de surgimento das obras antigas, "sob o céu grego", mas procura com isso definir um critério normativo, atemporal, um modelo a ser imitado sob um céu diferente. Há uma aporia, entre a singularidade do surgimento da arte antiga e o postulado da sua exemplaridade. Mesmo assim, o caráter histórico das investigações de Winckelmann influenciou decisivamente a estética posterior, de Herder a Hegel, e o desenvolvimento da história da arte voltado para a compreensão das obras em sua particularidade. Szondi ressalta que as Reflexões se opõem à abstração das teorias normativas sobre a arte, ao oferecer uma interpretação concreta das esculturas, a partir da descrição e da consideração do contexto cultural, geográfico e climático em que surgiram. Nesse sentido, o escrito remete ao diálogo com artistas, com a atenção voltada para prática e a técnica, em lugar da formulação de regras gerais abstratas.

Quanto à imitação dos antigos, embora sua defesa de fato se revele como uma formulação normativa, uma regra que contradiz o caráter histórico da arte, é preciso ressaltar o propósito mais concreto de um questionamento do aprendizado e da prática artística. O ponto de partida de Winckelmann é uma crítica aos caminhos tomados pela arte de sua época, marcada pelo estilo barroco e pela cópia da natureza nos quadros dos pintores holandeses. Essa arte se encontrava, segundo sua perspectiva, em franca decadência quando comparada às obras-primas do Renascimento e da Antigüidade grega. Por isso, ele indica aos estudantes e aprendizes uma outra via, diferente daquela defendida pelo escultor barroco Bernini, "que recomendava sempre aos jovens artistas estudar preferencialmente a natureza". Winckelmann questiona a 
maneira de compreender a noção tradicional, de base aristotélica, da arte como "imitação da natureza". Esse questionamento diz respeito à interpretação da mímese, noção que corre o risco de se degenerar no sentido mais fraco de mera cópia. De acordo com o texto das Reflexões:

A imitação do belo na natureza concerne ou bem a um objeto único ou então reúne as notas de diversos objetos particulares e faz deles um único todo. $\mathrm{O}$ primeiro processo implica fazer uma cópia semelhante, um retrato; é o caminho que conduz às formas e figuras dos holandeses. O segundo é o caminho que leva ao belo universal e suas imagens ideais; esse foi o seguido pelos gregos. ${ }^{6}$

O segundo caminho, o caminho seguido pelos gregos, é apresentado como um "caminho mais curto" para apreender o belo. Uma vez que a relação mesma do homem moderno com a natureza seguiria aquele primeiro processo, limitado à visão de objetos particulares, seria necessário aprender, ou imitar, a via de uma outra relação com a natureza. Winckelmann descreve o caminho de síntese seguida pelos gregos, a fim de mostrar como a "imitação do belo" vai além daquilo que naturalmente se oferece à visão. No começo de seu escrito, ele se refere ao aprendizado da arte na Grécia, considerada como um lugar em que a beleza natural se mostrava "sem encobrimentos". Segundo uma investigação das condições de surgimento da escultura grega, a escola dos artistas seriam os ginásios, nos quais os jovens se exercitavam sem roupa, de modo que a beleza dos seus corpos podia ser observada nas mais variadas posições. Para Winckelmann, a observação possibilitada nos ginásios, aliada às condições climáticas favoráveis, aos hábitos da época e à elevação do espírito, teria levado a uma imitação que vai muito além da mera cópia nos exercícios acadêmicos de observação. A partir das ocasiões numerosas de observar o belo na natureza (os corpos despidos dos jovens), os artistas gregos teriam começado a formar conceitos gerais da beleza presente nas partes e proporções do corpo humano, com base em um modelo de natureza espiritual, em uma idéia de perfeição ligada não mais ao humano, mas ao divino.

Winckelmann exemplifica a superação da semelhança com a natureza em duas estátuas gregas: o Antinous Admirandus, cujo corpo perfeito a própria natureza estaria longe de criar, e o Apolo de Belvedere, que põe diante dos nossos olhos "as proporções mais do que humanas de uma bela divindade", algo que mesmo a nossa imaginação não pode superar. $\mathrm{O}$ autor acredita que a imitação dessas obras poderia ensinar mais rapidamente o que é o belo, pois o artista encontra, na primeira escultura, "a soma do que está disperso em toda 
a natureza", e aprende, pela segunda, "a que ponto a mais bela natureza pode elevar-se acima de si própria, destemida e sabiamente". Portanto, a defesa da imitação dos antigos por parte de Winckelmann não diz respeito à mera cópia das estátuas, mas à compreensão do belo ideal que as torna um modelo a ser seguido. O que se deve imitar é o caminho de imitação tomado pelos gregos, de modo que, ao propor o modelo da arte antiga no lugar do modelo da natureza, o autor na verdade pretende reformular e revigorar a própria relação entre arte e natureza.

A famosa frase "O único caminho para nos tornarmos grandes e, se possível, inimitáveis, é a imitação dos antigos..." só pode ser interpretada corretamente a partir dessa diferença entre imitação e cópia. Há um caráter contraditório evidente nessa formulação, uma vez que os antigos são considerados pelo autor, mais do que grandes, inigualáveis, inimitáveis, mas são indicados como modelo a ser imitado. Em outras palavras, o que Winckelmann propõe, a partir de sua constatação da grandeza da arte antiga e da decadência da arte moderna (o Barroco, a pintura holandesa) é um caminho para alcançar a grandeza, "se possível" uma grandeza tão "inimitável" quanto a dos gregos. O caráter contraditório só leva a uma aporia se a imitação for compreendida como cópia, porque a pergunta acerca da possibilidade de imitar o inimitável ficaria sem solução. No entanto, o próprio autor esclarece a diferença entre os dois sentidos da "imitação do belo na natureza" e indica, assim, o modelo de um caminho a ser aprendido, a partir da observação e da compreensão da arte antiga em sua relação com a beleza. Não se trata da reprodução da arte grega, mas do aprendizado de sua grandeza exemplar e do ideal de perfeição que constitui a sua meta. O caminho da arte antiga é definido como aquele que "leva ao belo universal e suas imagens ideais", para além da mera semelhança com a natureza. Ao seguir essa via, a arte reúne as notas dispersas das belezas particulares e é capaz de criar uma beleza superior, de dar forma não mais ao belo corpo humano, mas à divindade.

O belo ideal é a segunda das noções fundamentais, ao lado da imitação dos antigos, que articulam a teoria defendida nas Reflexões. Ele encontra a formulação de seu caráter específico no trecho:

Enfim, o traço geral preponderante das obras-primas gregas é uma nobre simplicidade e uma calma grandeza, tanto na postura quanto na expressão. Assim como a profundeza do mar permanece tranqüila, por mais tempestuosa que esteja a superfície, a expressão nas figuras dos gregos mostra, em meio a todas as paixões, uma alma grande e comedida. ${ }^{7}$ 
As noções de nobre simplicidade e calma grandeza, identificadas como "o traço geral preponderante das obras-primas gregas", seriam retomadas posteriormente no contexto do helenismo que marcou a cultura alemã. Nessa formulação de Winckelmann, há dois elementos constituintes do caráter das obras-primas gregas, caráter que não diz respeito propriamente à forma, mas à alma revelada por meio da expressão do rosto e da postura do corpo nas esculturas. O primeiro elemento, a nobre simplicidade, pode ser entendido em contraposição ao rebuscamento e à complexidade exagerada do Barroco, já que o autor defende a forma simples, sem muitos acessórios, da arte antiga. Essa simplicidade deve ser associada à contenção, ao comedimento, como manifestações de uma nobreza da alma. Já no caso do segundo elemento, atribui-se a uma característica identificada na arte antiga, a sua grandeza, a qualidade da calma, da serenidade. A expressão tranqüila do rosto mostra, como esclarece a comparação feita na frase seguinte, a grandeza da alma.

Em sua análise das Reflexões, Szondi chama a atenção para a comparação com o mar, feita por Winckelmann para esclarecer sua definição do traço preponderante da arte grega. ${ }^{8}$ Trata-se de uma metáfora que estabelece uma inversão de idéias, quase um oxímoro, uma vez que a expressão do rosto, tranqüila, é comparada com a profundeza do mar, enquanto a alma agitada por paixões é comparada à superfície tempestuosa. Causaria menos estranhamento a comparação da face com a superfície, e da alma, com o fundo, para manter a relação entre interno e externo. Em todo caso, a metáfora indica uma idéia clara a respeito da definição precedente: a expressão do rosto se mantém tranqüila, por mais que se agitem as paixões da alma. Nessa tranqüilidade se revelam o comedimento e a grandeza a que o autor se referia em sua definição do caráter das obras-primas gregas.

Seguindo o seu procedimento ao longo de toda a obra, Winckelmann procura em seguida demonstrar sua definição a partir da descrição de uma escultura, no caso o Laocoonte, grupo estatuário que se tornaria um exemplo clássico para a reflexão acerca do sublime na arte. Atualmente se sabe da existência de um original grego de bronze, mas no século XVIII só era conhecida a cópia romana de mármore, encontrada em 1506 na capital italiana e abrigada no Vaticano, onde até hoje pode ser vista. Laocoonte é o sacerdote troiano que foi incumbido de realizar um sacrifício a Posseidon, quando os gregos simularam sua partida da costa e se esconderam no célebre cavalo de madeira deixado como presente para o rei Príamo. Como Virgílio conta 
na Eneida (II, 20), quando estava na iminência de revelar a presença dos guerreiros gregos no interior do cavalo de Tróia, o sacerdote foi castigado pelos deuses por meio de uma serpente gigantesca, que o matou junto com seus dois filhos. O grupo estatuário descrito e analisado por Winckelmann representa o pai e as crianças, presos pelos anéis da serpente. Na expressão do rosto do sacerdote troiano se revela, para o autor das Reflexões, a alma grande e comedida que corresponde ao belo ideal.

Winckelmann observa que, nessa escultura, o mais intenso sofrimento é descoberto "em todos os músculos e tendões do corpo", de modo que "quase acreditamos sentir em nós mesmos diante do abdome dolorosamente contraído" a dor de Laocoonte. No entanto, essa dor se manifesta "sem nenhuma raiva no rosto e na posição como um todo", o que caracterizaria a maneira como o sacerdote suporta o sofrimento: "A dor do corpo e a grandeza da alma são distribuídos com o mesmo vigor em toda a construção da figura. Laocoonte sofre, mas sofre como o Filoctetes de Sófocles: sua desgraça atinge a nossa alma, mas desejaríamos poder suportar a desgraça como esse grande homem". ${ }^{9}$ Nesse contexto, o autor faz uma crítica a Virgílio, por contar na Eneida que o sacerdote troiano solta um "grito terrível", que não é representado na estátua, pois a abertura da boca indicaria muito mais um "suspiro lamentoso". O suspiro de quem suporta a dor manifestaria a grandeza da alma, em uma expressão bela do sofrimento, enquanto o grito da versão do poeta latino desfiguraria a face.

O mesmo ideal de beleza descoberto na escultura é atribuído, nas Reflexões, à poesia antiga, na qual Winckelmann identifica a nobre simplicidade e a calma grandeza como o traço autêntico dos escritos gregos da época clássica. Essa atribuição se revelaria problemática para Lessing, cuja distinção das fronteiras entre a literatura e as artes plásticas explica as influências divergentes que os escritos de Winckelmann tiveram sobre a cultura alemã do final do século XVIII. A partir das diferenças estabelecidas por Lessing, em sua discussão com a teoria elaborada nas Reflexões, é possível esclarecer como os ideais defendidos nessa obra tiveram um desdobramento distinto na poesia e nas artes plásticas.

No movimento neoclássico, que se iniciava no campo das artes plásticas e da arquitetura, o princípio de imitação dos antigos se associava a uma reprodução fria e acadêmica das proporções da arte antiga. Nesse caso, não se trata da imitação do belo ideal, mas da cópia da forma da arte antiga, 
contrariando o fundamento do classicismo winckelmanniano. Já na literatura, toda a tradição do helenismo alemão, que marcou a cultura dos séculos seguintes, e especialmente o Classicismo em Weimar, com Goethe e Schiller, revela uma profunda influência das idéias de Winckelmann. A fase clássica da produção dos dois grandes nomes da literatura alemã naquela época, quando comparada ao movimento neoclássico, está muito mais de acordo com o sentido da frase "o único caminho para nos tornarmos grandes, se possível inimitáveis, é a imitação dos antigos".

Como afirma E. M. Butler, em seu estudo A tirania da Grécia sobre a Alemanha, "a Grécia de Winckelmann foi o fator essencial no desenvolvimento da poesia alemã ao longo da segunda metade do século XVIII e de todo o século XIX" ${ }^{10}$ É possível estender essa afirmação à filosofia, lembrando por exemplo o modo como Nietzsche valoriza os esforços de seus precursores para compreender os gregos antigos. Em O nascimento da tragédia, o filósofo se refere à "nobilíssima luta de Goethe, Schiller e Winckelmann pela cultura" como o tempo em que o espírito alemão se esforçou com mais vigor para aprender dos gregos. ${ }^{11} \mathrm{~A}$ aspiração de "chegar por uma mesma via à cultura e aos gregos" se tornou cada vez mais fraca na Alemanha depois disso, segundo Nietzsche, o que justificaria seu próprio esforço de compreensão dos gregos quase um século depois do Classicismo de Weimar. A fim de definir a relação dos gregos com o pessimismo, seu "anseio do feio", suas imagens de "tudo quanto há de mais terrível, maligno, enigmático, aniquilador e fatídico no fundo da existência", ${ }^{12}$ Nietzsche questiona a concepção resultante dos esforços dos autores do século anterior. No entanto, esse questionamento não abandona a concepção anterior, mas a incorpora a uma perspectiva mais abrangente, que inclui, ao lado do impulso apolíneo delineado pelos grandes nomes da literatura alemã do século XVIII, o impulso dionisíaco.

Se para Winckelmann a Grécia era uma imagem de perfeição, segundo uma perspectiva que valoriza o caráter luminoso, solar, apolíneo da arte grega antiga, foi a retomada dessa concepção apolínea por Goethe e Schiller, ampliando o campo de visão para um território que abrange também a literatura, que estabeleceu o modelo da cultura grega como ideal de beleza. Assim, a expressão "a Grécia de Winckelmann”, formulada por Butler, define a concepção inicial do projeto de imitação dos antigos que fundamentou não 
só o Classicismo alemão na literatura do final do século XVIII, como também o helenismo característico do pensamento alemão moderno.

\section{Referências}

BORNHEIM, Gerd. Páginas de filosofia da arte. Rio de Janeiro: Uapê, 1998.

BUTLER, E. M. The tiranny of Greece over Germany. Cambridge: University Press, 1935.

CARPEAUX, Otto Maria. Literatura alemã. São Paulo: Nova Alexandria, 1994.

ECKERMANN. Conversações com Goethe. Lisboa: Vega, [s.d.].

GOETHE, Wolfgang. Werke in sechs Banden. Frankfurt: Insel, 1993.

GOETHE, Wolfgang. Winckelmann. In: STAIGER, Emil (Herausg.). Vermischte Schriften. Frankfurt: Insel, 1965. Sechster Band.

GOETHE, Wolfgang. Essays on art and literature: The Collected Works. New Jersey: Princeton University Press, 1994. v. 3.

GOETHE, Wolfgang. Viagem à Itália. São Paulo: Companhia das Letras, 1999.

GOETHE; SCHILLER. Der Briefwechsel zwischen Goethe und Schiller. Frankfurt: Insel, 1977.

GUINSBURG, J. (Org.). O Classicismo. São Paulo: Perspectiva, 1995.

HERDER, J. G. Werke, Band I: Herder und der Sturm und Drang (1764-1774). Munique: Carl Hanser, 1984.

HERDER, J. G. Sämtliche Werke. Nachdruck der Ausgabe. Berlin 1892. Hildesheim 1967.

LESSING. Laocoonte ou sobre as fronteiras da pintura e da poesia. São Paulo: Iluminuras, 1998.

MACHADO, Roberto. O nascimento do trágico. Rio de Janeiro: Zahar, 2006.

NIETZSCHE, Friedrich. Werke in drei Bänden. Munique: Hansen, 1994.

NIETZSCHE, Friedrich. O nascimento da tragédia. Tradução de J. Guinsburg. Rio de Janeiro: Companhia das Letras, 1993.

SCHILLER, Friedrich. Cartas sobre a educação estética do homem. São Paulo: Iluminuras, 1990.

SCHILLER, Friedrich. Poesia ingênua e sentimental. São Paulo: Iluminuras, 1995.

STAËL, Madame de. De l'Allemagne. Paris: Garnier-Flamarion, 1968.

SZONDI, Peter. Poetik und Geschichtsphilosophie I. Studienausgabe der Vorlesungen Band 2. Frankfurt am Main: Suhrkamp, 1974.

SZONDI, Peter. Poetik und Geschichtsphilosophie II. Studienausgabe der Vorlesungen Band 3. Frankfurt am Main: Suhrkamp, 1974.

WINCKELMANN. Réflexions sur l'imitation des euvres grecques en peinture et sculpture. Alerçon (Orne): Aubier, 1990. (Coleção bilíngüe)

WINCKELMANN. History of the art of Antiquity. Los Angeles: Texts and Documents, 2006. 